\title{
M icropropagation of Dendrocalamus strictus nees from mature nodal explants
}

\author{
B. N. Pandey* and N. B. Singh \\ Plant Physiology Laboratory, Department of Botany, University of Allahabad, Allahabad - 211 002, INDIA \\ *Department of Botany, Government PG College, Lansdowne, Pauri Garhwal - 246 139, INDIA \\ *Corresponding author. E-mail: drpandeybn@yahoo.co.in
}

\begin{abstract}
An effort has been made to propagate Dendrocalamus strictus Nees using nodal explants from mature plants. The explants, after surface sterilization, were inoculated on solidified MS basal medium with $2 \mathrm{mg} / \mathrm{l} \mathrm{BAP}$. The buds, which started growing, were transferred to solidified MS basal medium with $4 \mathrm{mg} / \mathrm{BAP}$ and $15 \mathrm{mg} / \mathrm{l}$ AdS to achieve about three fold multiplication. Single shoots or 2-shoot clusters did not survive and therefore all the experiments were conducted with a cluster of minimum 3-shoots. The rooting was found difficult. Three hormones viz. IAA, IBA and NAA with a concentration of 1,3 and $5 \mathrm{mg} / \mathrm{l}$ were used in various combinations for rooting. Out of the total 9 treatments, only $20 \%$ rooting was found only in one treatment, namely in the medium with $5 \mathrm{mg} / \mathrm{l}$ indole butyric acid (IBA).
\end{abstract}

Keywords: Bamboo, Dendrocalamus strictus, Micropropagation, Nodal explants

\section{INTRODUCTION}

Bamboo is a perennial woody grass of family Poaceae. Dendrocalamus strictus Nees is the hardiest of all the Indian bamboos that withstand temperatures from $-5^{\circ} \mathrm{C}$ to $45^{\circ} \mathrm{C}$ and grows practically in all kinds of soils provided it is well drained (Sastri, 1952). The culm of D. strictus is valued greatly because it is thin, straight and strong for general use. Pulp contains about $85 \%$ cellulose and is used in paper industry (Vatsala, 2003). Being hardy, it is recommended for reclamation of ravine lands (Chaturvedi, 1986).

Propagation by seeds is not a reliable method due to the long and unpredictable flowering cycle, poor seed setting, short seed dormancy period, high seed sterility, low seed viability, high seed-borne infections and large-scale consumption by wild animals especially rodents. For these reasons, conventionally, vegetative methods are more commonly used for bamboo propagation. But, difficulty in transportation of vegetative propagules due to bulky size and the availability of required number of quality propagules is again the limiting factor for largescale bamboo plantation. Therefore, for generating planting stock in large quantities plant tissue culture methods of clonal propagation i.e. micropropagation is desired (Paranjothy et al., 1990). Micropropagation not only ensures the supply of quality planting material on regular basis but storage of germplasm in the form of in vitro cultures has been an additional advantage (Paranjothy et al., 1990; Arya et al., 2006).

Bamboo micropropagation has certain limitations, especially when explants from adult plant are used, the major problem being the induction of roots (Paranjothy et al., 1990). This is why most of the reports of micropropagation of $D$. strictus have used seedling explants. The use of mature nodal explants is desired because it ensures that the in vitro raised plants are truly clonal. This investigation attempts micropropagation of $D$. strictus, using nodal explants from mature plant.

\section{MATERIALS AND METHODS}

The primary shoots were collected from about 3-year old clumps of D. strictus, growing in the campus of IFFCO, Phulpur, Allahabad, in the month of July-August. They were cut into single-node segments. The basal sheath, covering the axillary bud was removed. These nodal explants were thoroughly washed under running tap water. They were then washed in 5\% labolene solution with few drops of Tween-20 for 15 minutes and rinsed with distilled water. Further surface sterilization of the explants was done under laminar airflow by the following two methods: (i) the explant was treated with $0.2 \% \mathrm{HgCl}_{2}$ solution for 10,15 and 20 minutes; it was thoroughly washed with sterile distilled water; it was then given a 30 second dip in $70 \%$ ethanol and again rinsed in sterile distilled water; (ii) the explant was treated for 10,15 and 20 minutes with calcium hypochlorite $\left[\mathrm{Ca}(\mathrm{OCl})_{2}\right]$ with few drops of Tween-20. After treatment explant was washed with sterile distilled water; it was then given a 30 second dip in $70 \%$ ethanol and again rinsed in sterile distilled water.

The explant was then inoculated on solidified MS basal medium $(0.75 \%$ agar at $5.8 \mathrm{pH})$ with $3 \%$ sucrose and $2 \mathrm{mg}$ 
/ 1 BAP. The cultures were incubated under controlled temperature $\left(27 \pm 2^{\circ} \mathrm{C}\right)$, light (2000-lux) and humidity (70 $\% \mathrm{RH})$ in a culture room. The observation was taken after 1 week for percent aseptic buds and after 3 weeks for percent bud breaks out of the aseptic buds in Table 1 . Single shoots and group of 2-, 3- and 4-shoots, produced at Stage I, were transferred to multiplication medium for multiplication. Since single shoots or 2-shoot clusters did not survive, all further experiments were conducted with a cluster of minimum 3-shoots. Multiplication medium consisted of solidified MS basal medium with 3\% sucrose and with different hormonal treatments. Observation was taken after 4 weeks for shoot multiplication (in fold i.e. number of shoots produced per initial 3-shoot cluster) and shoot length in Table 2.

Experiments on in vitro rooting were conducted on clusters, produced in stage II, with minimum 3-shoots of more than $2 \mathrm{~cm}$ length. Smaller shoots were again passed through stage II. Experiments were conducted on solidified MS basal with $3 \%$ sucrose. Three hormones viz. IAA, IBA and NAA at with 1,3 and $5 \mathrm{mg} / \mathrm{l}$ were used for rooting.

Rooted shoots from 4-6 week old cultures were taken out from the solidified medium very carefully so that the roots were not damaged. The roots were washed very gently under running tap water to remove any adhering agar. The plantlets were put in test tubes containing modified Knop's solution. They were covered with transparent polythene bags with a small hole at the top and were kept in culture room conditions. After 4 days the size of holes were increased. After 1 week the mouth of the polythene was opened. After 2 weeks the polythene bags were totally removed. After 3 weeks plantlets were transferred to small plastic cups with autoclaved potting mixture containing soils, sand and FYM (2:1:1). They were irrigated once with Knop's solution and then with water as and when needed. The plantlets were kept in the culture room for another 1 week and then they were shifted to glasshouse.

There were five replicates in each treatment. Each experiment was conducted three times. The data shown is the mean value from all the replicates.

\section{RESULTS}

The effect of the two sterilizing agents is shown in Table 1. Of the two sterilizing agents, $0.2 \%$ mercuric chloride produced larger number of aseptic explants as well as higher percentage of bud break. Mercuric chloride treatment for 20 minutes gave the highest percentage of aseptic buds $(53.33 \%)$ but maximum bud break $30 \%$ $(69.23 \%)$ was in the 15 -minute treatment. Aseptic buds were $30 \%$ in 10-minute treatment and $43.33 \%$ in 15-minute treatment. Bud break was $20 \%$ (66.67\%) in 10-minute treatment and $26.67 \%$ (50\%) in 20-minute treatment.
Calcium hypochlorite gave maximum aseptic buds (26.67\%) in treatment for 20 minutes, but maximum bud break $13.33 \%$ (57.14\%) was in the treatment for 15 minutes. Aseptic buds were $13.13 \%$ in 10-minute treatment and $23.33 \%$ in 15 -minute treatment. Bud break was $6.67 \%$ $(50 \%)$ in 10 -minute treatment and $10 \%(37.5 \%)$ in 20 minute treatment.

The effect of different hormonal treatments for shoot multiplication is shown in Table 2. It shows that $3 \mathrm{mg} / \mathrm{l}$ BAP produced 1.33 fold shoot multiplication. Increase of BAP to $4 \mathrm{mg} / \mathrm{l}$ gave shoot multiplication 2.33 fold. Further increase of BAP to $5 \mathrm{mg} / \mathrm{l}$ did not increase the rate of multiplication. Addition of $15 \mathrm{mg} / \mathrm{l}$ adenine sulphate (AdS) along with $4 \mathrm{mg} / \mathrm{l}$ BAP produced maximum shoot multiplication (3.33 fold). Increase of AdS to 25 $\mathrm{mg} / \mathrm{l}$ and addition of IAA at low concentration $(0.5 \mathrm{mg} / \mathrm{l})$ decreased the multiplication to 2.67 and 2.00 fold respectively. $3 \mathrm{mg} / \mathrm{l}$ BAP gave maximum shoot length $(3.53 \mathrm{~cm})$. Further increase of BAP or addition of AdS or IAA did not increase the shoot length. Shoot length was $3.08 \mathrm{~cm}$ at $4 \mathrm{mg} / \mathrm{l} \mathrm{BAP} ; 3.04 \mathrm{~cm}$ at $5 \mathrm{mg} / 1 \mathrm{BAP} ; 2.57 \mathrm{~cm}$ at $4 \mathrm{mg} / \mathrm{l} \mathrm{BAP}$ and $15 \mathrm{mg} / \mathrm{l} \mathrm{AdS} ; 2.58 \mathrm{~cm}$ at $4 \mathrm{mg} / \mathrm{l} \mathrm{BAP}$ and $25 \mathrm{mg} / \mathrm{l} \mathrm{AdS}$; and $2.03 \mathrm{~cm}$ at $4 \mathrm{mg} / \mathrm{l} \mathrm{BAP}, 15 \mathrm{mg} / \mathrm{l} \mathrm{AdS}$ and $0.5 \mathrm{mg} / \mathrm{l} \mathrm{IAA}$.

Rooting was found very difficult. Out of the nine treatments involving three auxins viz. IAA, IBA and NAA at three different concentrations viz. 1,3 and $5 \mathrm{mg} / \mathrm{l}$, only $5 \mathrm{mg} / \mathrm{l} \mathrm{IBA}$ produced $20 \%$ rooting and all other treatments did not even show any sign of rooting. The rooted plantlets were acclimatized and were shifted to glass house for field transfer. Seventy per cent of the plants could reach glass house.

\section{DISCUSSION}

Recalcitrance of adult trees, including bamboos, is a serious problem with micropropagation. Most of the success achieved, either by shoot formation or by embryo formation, has been only with juvenile tissue (zygotic embryo and seedling explants) because juvenile explants are more readily established in culture and growth and proliferation at a more rapid rate than adult material. The new sprouts of the year from adult trees/bamoos are considered to be relatively juvenile. But, adult plant has proven the quality, and therefore, for clonal propagation explants from adult plant should be the material of choice (Thorpe et al.,1991; George, 1993).

For micropropagation most of the workers have used nodal segments from seedlings (Nadgir et al., 1984; Saxena, 1990; Das and Rout, 1991; Ansari et al., 1996; Maity and Ghosh, 1997; Yashoda et al., 1997). Only some workers have reported micropropagation from nodal segments from mature field-grown clumps (Chaturvedi et al., 1993; Arya and Sharma, 1998). In the present investigation, single nodal segments from the primary 
Table 1. Effect of different surface sterilization treatments on explants of D. strictus.

\begin{tabular}{lcc}
\hline Treatment & Aseptic buds (\%) & Bud break (\%)* \\
\hline $\mathrm{HgCl}_{2}-10$ minutes & 30.00 & $20.00(66.67)$ \\
$\mathrm{HgCl}_{2}-15$ minutes & 43.33 & $30.00(69.23)$ \\
$\mathrm{HgCl}_{2}-20$ minutes & 53.33 & $26.67(50.00)$ \\
$\mathrm{Ca}(\mathrm{OCl})_{2}-10$ minutes & 13.13 & $6.67(50.00)$ \\
$\mathrm{Ca}(\mathrm{OCl})_{2}-15$ minutes & 23.33 & $13.33(57.14)$ \\
$\mathrm{Ca}(\mathrm{OCl})_{2}-20$ minutes & 26.67 & $10.00(37.50)$ \\
\hline
\end{tabular}

*The figures in parentheses show the percentage of bud break with respect to aseptic bud.

Table 2. Effect of different hormonal treatments on multiplication of D. strictus.

\begin{tabular}{lcc}
\hline Treatment $(\mathrm{mg} / \mathrm{l})$ & Shoot multiplication (fold) & Shoot length (cm) \\
\hline 2 BAP & 1.00 & 2.10 \\
3 BAP & 1.33 & 3.53 \\
4 BAP & 2.33 & 3.08 \\
5 BAP & 2.00 & 3.04 \\
4 BAP + 15 AdS & 3.33 & 2.57 \\
4 BAP + 25 AdS & 2.67 & 2.58 \\
4 BAP + 15 AdS + 0.5 IAA & 2.00 & 2.03 \\
\hline
\end{tabular}

shoots of about 3-year old clumps of Dendrocalamus strictus were used as explants. Out of the six sterilizing treatments, 15 -minute treatment with $0.2 \%$ mercuric chloride proved to be the most effective, producing highest number of bud break. Many workers have found mercuric chloride satisfactory (Nadgir et al., 1984; Saxena, 1990; Das and Rout, 1991). Others have used sodium chlorite and chlorine water for surface sterilization (Rao et al., 1985; Yeh and Chang, 1986 a,b). There is one report of use of sodium hypochlorite and mercuric chloride successively (Yashoda et al., 1997).

The explant was inoculated on agar-solidified MS basal medium $(0.75 \%$ agar at $5.8 \mathrm{pH})$ with $3 \%$ sucrose and $2 \mathrm{mg}$ / 1 BAP. MS medium has also been used for establishment of bamboo culture by most of the workers (Nadgir et al., 1984; Das and Rout, 1991; Maity and Ghosh, 1997; Arya and Sharma, 1998). Presence of a cytokinin, mostly BAP, has been found essential for bud break in bamboo (Nadgir et al., 1984; Banik, 1987 and Saxena, 1990).

In this study, the problem of browning was experienced like many others who reported browning of medium with mature bamboo shoots (Zamora et al., 1989). But by quick transfer of explants on fresh medium the problem was controlled successfully. For multiplication, single shoots and group of 2-, 3- and 4-shoots were used. But, single shoot or 2-shoot cluster did not survive; therefore all further experiments were conducted with a cluster of minimum 3-shoots. This is in conformity with the report that propagules of 3-4 shoots showed better In vitro rooting and transplantation survival (Yashoda et al., 1997). BAP at three concentrations viz. 3, 4 and $5 \mathrm{mg} / \mathrm{l}$ were used for multiplication. The treatment of $4 \mathrm{mg} / \mathrm{l}$ gave shoot multiplication 2.33 fold. Further increase of
BAP did not increase the multiplication. BAP has been found the best cytokinin for shoot multiplication of bamboo D. strictus (Nadgir et al., 1984; Das and Rout, 1991; Chambers et al., 1991; Prutpongse and Gavinlertvatana, 1992; Ansari et al., 1996; Maity and Ghosh, 1997; Arya and Sharma, 1998). The combination of BAP with another cytokinin, kinetin, has been found to increase shoot multiplication in bamboo (Nadgir et al., 1984; Saxena, 1990). This investigation has also found synergistic effect of $15 \mathrm{mg} / \mathrm{l}$ Adenine Sulphate (AdS) with $4 \mathrm{mg} / \mathrm{l} \mathrm{BAP}$, which produced the maximum shoot multiplication 3.33 fold.

Higher multiplication in D. strictus has been reported with seedling explants. There is report (Das and Rout, 1991) of $23 \pm 2.3$ fold multiplication on MS with $3 \mathrm{mg} / \mathrm{l}$ $\mathrm{BAP}$ and $30 \mathrm{mg} / \mathrm{l}$ Adenine sulphate. But, with explants from old field-grown clumps, multiplication of shoots is restricted (Paranjothy et al., 1990; Chaturvedi et al ., 1993), using explants from 10-year old clumps, obtained only 24 fold shoots in D. strictus on MS with $0.5 \mathrm{mg} / \mathrm{l} \mathrm{IAA}$ and $15 \mathrm{mg} / \mathrm{l} \mathrm{AdS}$. There is report of reported 5-fold multiplication on MS supplemented with $3 \mathrm{mg} / \mathrm{l} \mathrm{BAP}$ in Bambusa bambos using nodal segments from 3-year-old plants (Arya and Sharma, 1998).

Addition of $0.5 \mathrm{mg} / 1 \mathrm{IAA}$ with BAP and AdS decreased the multiplication to 2.00 fold. There are reports that addition of auxins, IAA or NAA, has either no effect on multiplication or decreased the multiplication of bamboo (Saxena, 1990; Das and Rout, 1991; Prutpongse and Gavinlertvatana, 1992). 3 mg/l BAP gave maximum shoot length $(3.53 \mathrm{~cm})$. Further increase of BAP decreased the shoot length. This result is in agreement with those of other workers, who have also reported decrease in shoot 

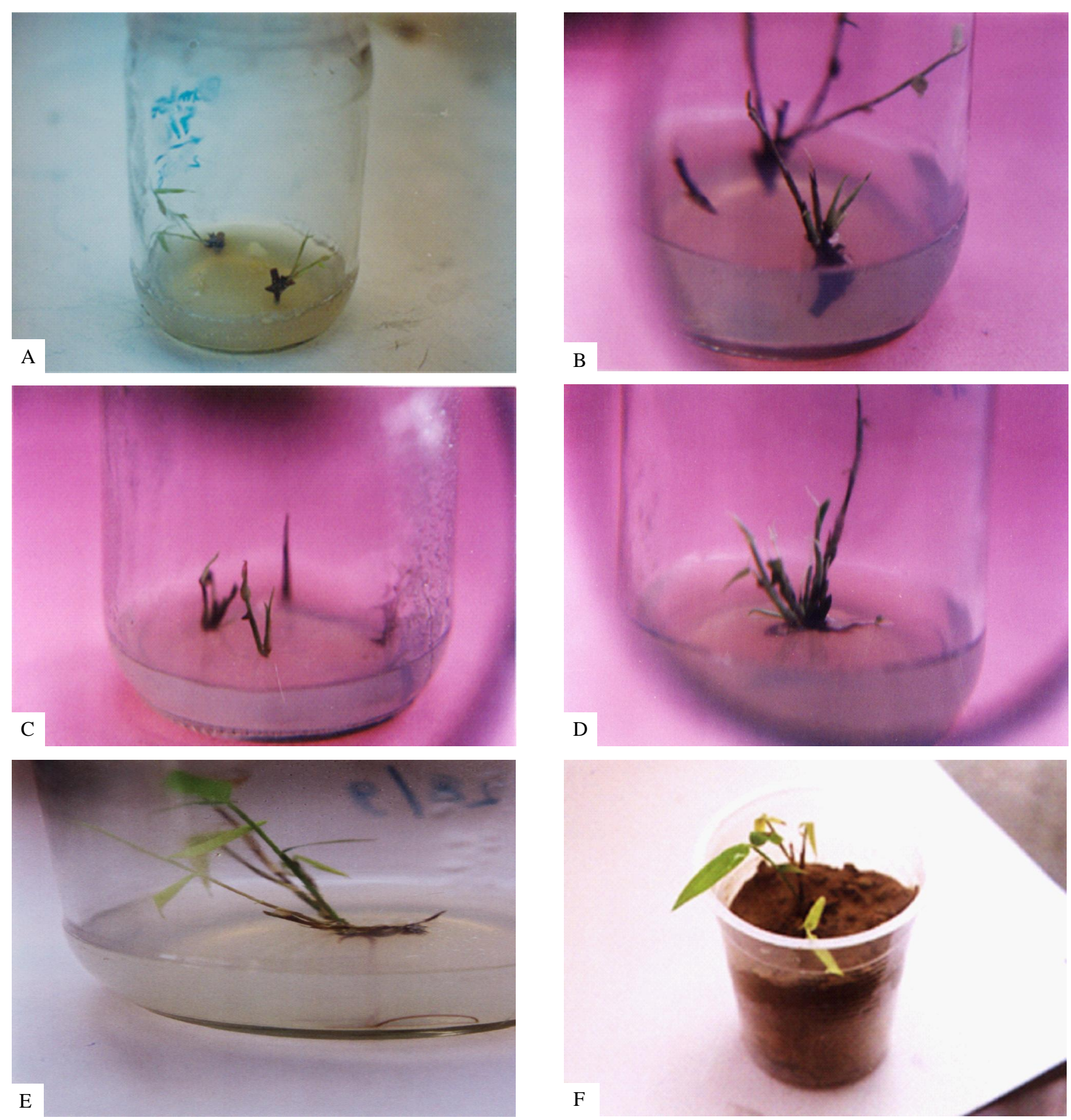

Fig. 1 (A-F). Micropropagation of D. strictus nees. (A-B) Establishment stage, (C-D) M ultiplication stage, minimum 3-shoot clusters survive and multi ply, (E) R ooting stage, root induction from shoots isolated from multiplication stage, and (F) Transplantation, in vitro raised plantlet transfer red to pot.

length with high concentrations of BAP (Prutpongse and Gavinlertvatana, 1992; Yashoda et al., 1997). Significant decrease in shoot length has also been noticed in this work with the combination of BAP with AdS or IAA.

Of the three auxins (IAA, IBA and NAA), with three different concentrations (1, 3 and $5 \mathrm{mg} / \mathrm{l})$, only $5 \mathrm{mg} / \mathrm{l}$ IBA produced $20 \%$ rooting. All other treatments did not even show any sign of rooting. Rooting has been found difficult in D . strictus, particularly with explants from old culms. Although multiplication of shoots is restricted

(Paranjothy et al., 1990), but where multiplication of shoots was possible efficient rooting remained a major bottleneck in establishment of a complete protocol for micropropagation (Nadgir et al., 1984; Dekkers and Rao, 1989) while working on D. strictus were able to obtain multiple shoots but very few of them could be rooted. Only 30\% rooting (Chaturvedi et al., 1993) in D . strictus has been reported with shoots inverted on MS supplemented with $1 \mathrm{mg} / \mathrm{lBA}, 1 \mathrm{mg} / \mathrm{l} \mathrm{NAA}, 0.5 \mathrm{mg} / 12$,4$\mathrm{D}$ and $1 \mathrm{mg} / \mathrm{l}$ phloroglucinol at $\mathrm{pH}$ 5.2. 
The rooted plantlets were acclimatized with $70 \%$ survival in this study. In $D$. strictus similar survival has been reported by different workers: $70-80 \%$ (Nadgir et al., 1984) and $80 \%$ (Chaturvedi et al.,1993). For other species slightly higher transplantation survival has been reported: $80-90 \%$ in Bambusa tulda (Saxena, 1990) and 80-90\% in Bambusa bambos (Arya and Sharma, 1998).

Bamboo Dendrocalamus strictus is economically very important. Besides being the poor man's timber, it is the most important raw material for paper mills and also it is most suitable for plantations on hill slopes and wastelands. Most of the bamboo produced is utilized for papermaking and it is about $60 \%$ of the demand. To meet out the demand India has to import newsprint, paperboard, wood and pulp worth Rs. 1,854 crores (Khoshoo, 1994). The gap in supply of raw material has led to closure of several paper mills in Philippines and India e.g. Ashok Paper Mill in Jogipura (Pathak et al., 2005). Because the conventional methods have their own limitations, tissue culture method can be adapted as an alternative to provide propagules in large number. Bamboo micropropagation has also limitations, especially with explants from adult plant. The major problem has been found during the induction of roots. However, the use of mature nodal explants is still desired because it ensures that the in vitro raised plants are truly clonal. Although this investigation achieved the micropropagation of $D$. strictus, using nodal explants from mature plant, further experiments are needed to reduce the cost.

\section{REFERENCES}

Ansari, S. A., Kumar, S. and Palanisami, K. (1996). Peroxidase activity in relation to in vitro rhizogenesis and precocious flowering in Bambusa arundinacea. Curr. Sci., 71: 358-359.

Arya, S. and Sharma, S. (1998). Micropropagation technology of Bambusa bambos through shoot proliferation. Ind. For., 9: 725-731.

Arya, S., Rana, P. K., Sharma, R. and Arya, I. D. (2006). Tissue culture technology for rapid multiplication of Dendrocalamus giganteus Munro. Ind. For., 132: 345-357.

Banik, R. L. (1987). Techniques of bamboo propagation with special reference to pre-rooted and pre-rhizomed branch cutting and tissue culture. In: A. N. Rao, G. Dhanraj and C. B. Shastry (Eds.), Recent research on bamboos, The Chinese Acad. For. and IDRC, Singapore.

Chambers, S. M., Heuch, J. H. R. and Pirrie, A. (1991). Micropropagation and in vitro flowering of the bamboo Dendrocalamus hamiltonii Munro. Plant Cell Tiss. Org. Cult., 27: 45-48.

Chaturvedi, A. N. (1986). Bamboos for farming. Uttar Pradesh Forest Bulletin, No.52., Lucknow.

Chaturvedi, H. C., Sharma, M. and Sharma, A. K. (1993). In vitro regeneration of $D$ endrocalamus strictus Nees. through nodal segments taken from field-grown culms. Plant Sci.,
92: 97-101.

Das, P. and Rout, G. R. (1991). Mass multiplication and flowering of bamboo in vitr o. O rissa J. H ort., 19: 118-121.

Dekkers, A. J. and Rao, A. N. (1989). Tissue culture of four bamboo genera. In: A. N. Rao and A. M. Yusoff (Eds.), Proc. Seminar on tissue culture of forest species. FRI, Malaysia and IDRC, Singapore.

George, E. F. (1993). Plant propagation by tissue culture, Vol. I. Exegetics Ltd., Edington, England.

Khoshoo, T. N. (1994). Making forestry sustainable. Curr Sci., 70: 205-214.

Maity, S. and Ghosh, A. (1997). Efficient plant regeneration from seeds and nodal segments of Dendrocalamus strictus using in vitro techniques. Ind F or., 4: 313-318.

Nadgir, A. L., Phadke, C. H., Gupta, P. K., Parshrami, V. A., Nair, S. and Mascarenhas, A. F. (1984). Rapid multiplication of bamboo by tissue culture. Silvae G enetica, 33: 219-223.

Paranjothy, K., Saxena, S., Banerjee, M., Jaiswal, V. S. and Bhojwani, S. S. (1990). Clonal multiplication of woody plants. In: S. S. Bhojwani (Ed.), Plant Tissue Culture: Application and Limitations. Elsevier, Amsterdam.

Pathak, K. C., Sharma, A. K., Hazarika, P. K., Neog, D. and Mishra, H. (2005). Genetic conservation and improvement work of bamboos at Rain Forest Research Institute, Jorahat, Assam. Ind F or., 131: 11.

Prutpongse, P. and Gavinlertvatana, P. (1992). In vitro micropropagation of 54 species from 15 genera of bamboo. Hort. Sci, 27: 453-454.

Rao, I. U., Rao, I. V. R. and Narang, V. (1985). Somatic embryogenesis and regeneration of plants in the bamboo, Dendrocalamus strictus. Plant Cell Rep., 4: 191-194.

Sastri, B.N. (1952). The Wealth of India: Raw Materials, Vol. III: D-E. Council of Scientific and Industrial Research, New Delhi Saxena, S. (1990). In vitro propagation of the bamboo (Bambusa tulda Roxb.) through shoot proliferation. Plant Cell Rep., 9: 431-434.

Thorpe, T. A., Harry, I. S. and Kumar, O. P. (1991). Application of micropropagation to forestry. In: P. C. Debergh and R H Zimmerman (Eds.), Micropropagation: technology and application. Kluwer, Dordrecht.

Vatsala. (2003). Bamboos in India. NISCAIR, New Delhi.

Yashoda, R., Sumathi, R., Malliga, P. and Gurumurthi, G (1997). Genetic enhancement and mass production of quality propagules of Bambusa nutans and Dendrocalamus membranaceus. Ind F or., 4: 303-306.

Yeh, M. L. and Chang, W. C. (1986a). Plant regeneration through somatic embryogenesis in callus culture of green bamboo (Bambusa oldhamii). Theor Appl G enet., 73: 161-163.

Yeh, M. L. and Chang, W. C. (1986b). Somatic embryogenesis and subsequent plant regeneration from inflorescence callus of Bambusa beecheyana Munro var. beecheyana. Plant Cell Rep., 5: 409-411.

Zamora, A. B., Gruezo, S. S. and Damasco, O. P. 1989. Callus induction and plant regeneration from internode tissues of Dendrocalamus latiflorus cv. Machiko. In: A. N. Rao and A. M. Yusoff (Eds.), Proc. of the seminar on tissue culture of forest species. FRI, Malaysia and IDRC, Singapore. 